\section{Spondylurus nitidus (Puerto Rican Skink).} Conservation.

Dates of observation: 4 June 2012, 4 October 2012, and 4 May 2013. Location: Guajataca State Forest, northwestern Puerto Rico. Coordinates: 18.420369, -66.966767. Voucher: image. Previously, this Puerto Rican endemic species had not been reliably reported from the island since 1980 (Hedges SB \& Conn CE, 2012, A new skink fauna from Caribbean islands [Squamata, Mabuyidae, Mabuyinae], Zootaxa, 3288, 1-244). One individual of this species was photographed on each of three visits to the area, which is in humid limestone forest. Approximately 30-40 lizards were seen at this general location since September 2011. They were most easily observed in the morning (0800-1200 hours), usually basking in the sun on limestone boulders, leaf litter, and fallen tree trunks. Lizards were not seen during cloudy, overcast conditions, especially in afternoons. When approached they often retreated into crevices, holes, and deep leaf litter. The introduced mongoose, believed to be the major threat to the survival of the species (Hedges SB \& Conn CE, 2012), was not observed in the area.
Alejandro J Sanchez, Condominio Los Olmos, Apto. 3-G, 36 Calle Nevarez, San Juan, PR 00927, USA, ajtgsm@onelinkpr.net.

Citation: Sanchez AJ. 2013. Spondylurus nitidus (Puerto Rican Skink). Conservation. Caribbean Herpetology 40:1.

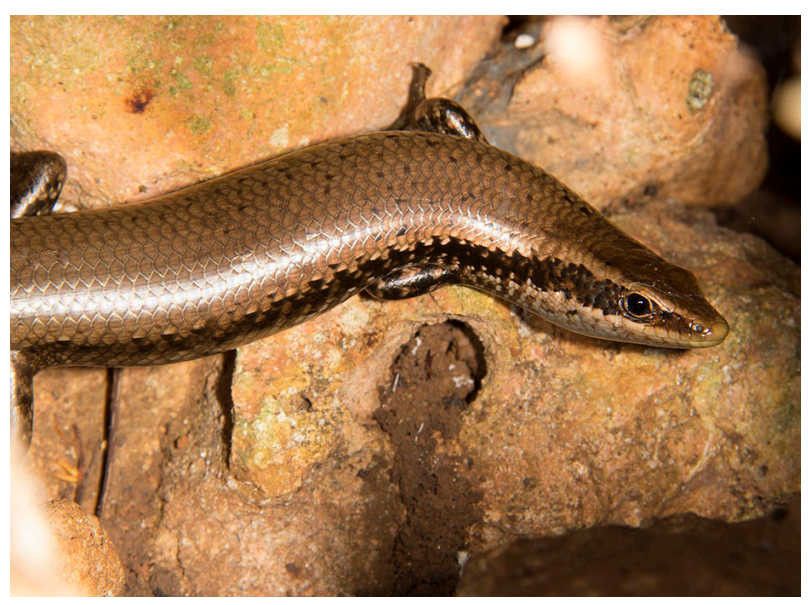

